\title{
Understanding unplanned readmissions for children undergoing surgery in a single pediatric general surgical department
}

\author{
Chao Zheng ${ }^{1}$, Hong Zhou', Hai Zhu1', Bailin Chen ${ }^{1,2}$, Lin Qiu ${ }^{1 *}$ and Chunbao Guo ${ }^{1,2^{*}}$ (D)
}

\begin{abstract}
Background: The aim of the current research was to investigate the unplanned readmission rates and identify the risk factors of unplanned readmissions in pediatric general surgical specialties.

Methods: A retrospective review of unplanned readmissions following initial surgery from July 1, 2010, to June 30, 2017, in the general surgical specialties at an academic tertiary care hospital was performed. The main outcome of interest was unplanned readmission rates, the common causes for readmission. The risk factors involved in the unplanned readmissions were further investigated using univariate and multivariate analyses.
\end{abstract}

Results: Of the 3263 patients who underwent surgery and discharge, 176 (9\%) were unplanned readmissions. The most frequent surgical operation related to readmission was appendectomy, and the common readmission causes were associated with treatment of gastrointestinal complaints/complications. Multivariable analysis demonstrated that emergency surgery $(p=0.016$, odds ratio $[\mathrm{OR}]=2.73 ; 95 \% \mathrm{Cl}=1.35-6.19)$, major complications $(p=0.042$, $\mathrm{OR}=2.43 ; 95 \% \mathrm{Cl}=1.12-4.71)$ and the initial hospital length of stay $(p=0.036, \mathrm{OR}=3.46 ; 95 \% \mathrm{Cl}=1.67-7.53)$ were independent risk factors for readmission.

Conclusions: This study identified potential risks for readmission, which should be targeted for interventions to improve quality and resource allocation.

Keywords: Unplanned readmissions, General surgical specialties, Hospitalization

\section{Background}

Recently, hospital readmission, the important metric for the quality measurement of patient care, was pushed forward due to pressure linked to payment [1-3]. Furthermore, a patient's unplanned readmission influences their quality of life and limits hospital resources. In 2008, the Medicare Payment Advisory Commission in the USA conducted payment reforms to encourage a reduction in unnecessary surgical readmissions and save health care costs $[4,5]$.

For surgical patients, the postoperative complications were the most reasons related to hospital readmission, which is fundamentally different from medical patients [6]. Because specific procedures carry high readmission

\footnotetext{
* Correspondence: qiulin118@126.com; guochunbao@cqmu.edu.cn; guochunbao@foxmail.com

${ }^{1}$ Department of Pediatric General Surgery, Children's Hospital, Chongqing Medical University, Chongqing, People's Republic of China

Full list of author information is available at the end of the article
}

risk, the causes of readmission for surgical patients are often associated with underlying surgical conditions, suggesting that there is an opportunity to identify the patients who carry the risk of readmission postoperatively and intervene this risk preoperatively.

Many studies have been carried out to investigate the risk profiles of readmission within precise patient populations, including older age patients [7-9]. These previous studies highlight that the readmissions might be preventable with comprehensive preoperative and postoperative care. However, there was a few research that point to unplanned surgical readmission among pediatric patients, and it was unclear whether all the reported factors carry the similar risk for surgical readmission among pediatric population.

The purpose of the current research is to examine the readmitted pediatric patients undergoing general surgical operations and define the factors related to unplanned 
readmission in the general surgical department among pediatric patient population.

\section{Methods}

\section{Patients and methods}

The current research is performed utilizing a patient database in the general surgical department at Chongqing Medical University Children's Hospital from July 1, 2010 to June 30, 2017. The electronic medical records of all patients for any unexpected readmissions within 30 days of the inpatient general surgery procedures (Table 1), and any documented reasons for the readmission were reviewed with two independent investigators who underwent our training. All the case and control samples and evidence of complicated appendicitis. The patients should age more than one month and less than 16 years. The unplanned readmissions were defined as readmissions for hospitalization occurring within a 30day period that starts on the day the patient is discharged, which is as a result of a complication directly or indirectly related to the initial surgical procedure regardless of whether it occurred within the same hospital admission. We excluded patients if two-stage surgeries or outpatient procedures were planned and if the readmission was the necessary planned treatment following their initial operation (like, chemotherapy). The patients death within 30 days of initial operation were also excluded for the readmission risk analysis.

During the same period at the same institution, the patients as control were identified from patients underwent the same operation without unplanned readmission as a given case with unplanned readmissions. In the

Table 1 Initial surgical compositions of unplanned readmission and its matched controls

\begin{tabular}{llll}
\hline Type of initial surgery & $\begin{array}{l}\text { Unplanned } \\
\text { readmission }\end{array}$ & $\begin{array}{c}\text { Control } \\
\text { Kasai procedure }\end{array}$ & $\begin{array}{l}\text { Total } \\
\text { cases (\%) }\end{array}$ \\
Hernia corrective surgery & 85 & 66 & $887(3.9)$ \\
Cholecystectomy & 5 & 14 & $616(1.3)$ \\
External drainage of biliary dilatation & 9 & 10 & $213(2.3)$ \\
Hepatic surgery & 2 & 17 & $147(6.1)$ \\
Roux-Y anastomosis & 8 & 4 & $28(7.1)$ \\
Appendectomy & 72 & 13 & $374(2.1)$ \\
Meckel diverticulum & 5 & 119 & $413(17.4)$ \\
Devascularization for CTPV & 4 & 8 & $4194(2.6)$ \\
Trauma laparotomy & 2 & 2 & $25(8.0)$ \\
Laparotomy & 21 & 42 & $250(8.4)$ \\
Pancreatic operation & 4 & 10 & $48(8.3)$ \\
Fistula close procedure & 1 & 2 & $27(3.7)$ \\
Total & 176 & 338 & $3263(5.4)$ \\
\hline CTPV Cavernous transformation of the portal vein & &
\end{tabular}

CTPV Cavernous transformation of the portal vein corresponding case, we randomly selected two immediately preceding patients who underwent the same principal procedure within six-month period around the surgery date. After reviewing the entire medical record, the independent investigators determined the reasons for the readmission according to the standard International Classification of Diseases (ICD-9), Ninth Revision code (e.g., surgical site infection [SSI], postoperative ileus).

\section{Study covariates}

We primarily evaluated the rate of unplanned readmission across the various specialties. We further investigated the factors related to unplanned readmission. We collected over 20 explanatory perioperative characteristic variables to explore the reasons for readmission, including patient demographics, preoperative morbidity variables, intraoperative variables, postoperative characteristics, including 30-day postoperative complications and unplanned readmission in the inpatient setting. The postoperative complications, which should be related with readmission, were further determined.

\section{Statistical analysis}

The data manipulations were performed using SPSS Version 20 (IBM Corp, Armonk, NY). First, we generated descriptive statistics to explore the frequency of unplanned readmissions following the initial general surgical procedures. Univariate analysis was utilized to examine patient explanatory perioperative variables among the patients with and without unplanned readmission. Continuous data with normal distribution were presented as the mean \pm (standard deviation) and assessed with a Student $t$ test, and nonnormally distributed variables were presented as the median (interquartile ranges) and tested using the Mann-Whitney $U$ test. Categorical data were expressed as frequencies (percentages) and analyzed using a Fisher's exact test or $\chi^{2}$ test, as appropriate. To determine independent factors related to unplanned readmission, Multivariable analysis was further carried out. Variables associated with unplanned readmissions with $p$ value $\leq 0.20$ in univariate analyses were forced into the multivariable analysis. Statistical significance was recognized if 2 -sided $P$ values were less 0.05 .

\section{Results}

\section{Patient readmission features}

There were 225 patients with readmission among 3263 patients who underwent general surgery procedures in our institute, with an overall readmission rate of $6.9 \%$, and $49(1.5 \%)$ readmissions were excluded because they were planned (18), unrelated (21) or self-discharged (interrupted managements due to some socioeconomic reasons) (10) at the index admission. Table 1 summarizes the 
features of readmissions, including the rates of readmission for specific diagnoses. There were 176 (5.4\%) unplanned readmissions, with an average age of 3.6 years.

\section{Procedures}

Unplanned readmission occurred following 22 different types of initial operations. Among them, 2 procedures accounted for almost half of all the unplanned readmissions. Readmission frequencies stratified by procedure type within our cohort are detailed in Table 1 . The readmission rates for individual procedures ranged from $1.3 \%(8 / 616)$ after hernia corrective surgery to $17.4 \%$ (72/413) after appendectomy.

\section{Reasons for unplanned readmission}

To evaluate for potentially preventable readmission, we then focused on reasons for unplanned readmission in pediatric general surgery patients. The common reasons for unplanned readmission were related to treatment for gastrointestinal (GI) complaints and complications (intestinal obstruction, nausea, vomiting, etc.) (31.8\%, $56 / 176)$, postoperative biliary tract infection $(18.2 \%$, 32/ 176) and surgical infections, including ileus (14.2\%, 25/ 176) or intra-abdominal abscess and infection (13.6\%, 24/176), followed by postoperative electrolyte disturbance $(3.4 \%, 6 / 176)$, and hernia relapse $(8.5 \%, 15 / 176)$. Among these reasons, gastrointestinal (GI) complaints and complications combined with postoperative biliary tract infection accounted for approximately half of all readmissions (Table 2).

The 18th day (1-30 days) after surgery was the median date for unplanned readmission (Table 2). Five of 176 cases $(2.8 \%)$ were readmitted the first day after surgery. The interquartile range of unplanned readmission was 16 days for GI complaints/complications, 21 days for postoperative biliary tract infection, and 14days for

Table 2 Reasons for unplanned readmission

\begin{tabular}{lll}
\hline Indication for readmissions & $\begin{array}{l}\text { First } \\
\text { readmission }\end{array}$ & $\begin{array}{l}\text { Median date of } \\
\text { readmission } \\
\text { (range) }\end{array}$ \\
\hline Alimentary tract hemorrhage & 7 & $7(1,29)$ \\
Anastomotic leakage & 4 & $4(3,6)$ \\
Wound dehiscence & 6 & $5(2,7)$ \\
Surgical site infection & 19 & $15(7,26)$ \\
Intra-abdominal abscess and infection & 14 & $9(5,29)$ \\
Postoperative electrolyte disturbance & 6 & $6(1,15)$ \\
Postoperative biliary tract infection & 21 & $18(6,30)$ \\
Postoperative ileus & 16 & $15(5,27)$ \\
Heinia relapse & 15 & $23(18,28)$ \\
Other & 7 & $21(3,25)$ \\
Total & 176 & $36(1,30)$ \\
\hline
\end{tabular}

intra-abdominal abscess and infection. When examining early unplanned readmission (within 7 days of discharge), a total of $25(4.0 \%)$ patients were readmitted. The top three reasons for early unplanned readmission were different (postoperative electrolyte disturbance, anastomotic leakage, and bleeding). Prior to readmission, the majority of patients with early unplanned readmission had an consultation with the initial surgical team.

\section{Case-control analysis for risk factors of readmission}

Under univariate analysis, factors related to unplanned 30-day readmission included operative blood loss $(p=$ 0.039), surgeon's skill level $(p=0.048)$, emergency surgery $(p=0.004)$, major complications $(p=0.008)$, infectious complications $(p=0.025)$, contaminated or dirty wound $(p=0.047)$ and the initial length of hospital stay $(p=0.011)$ (Table 3$)$. No statistically significant differences were noted in terms of age, sex, and operative time.

Multivariable independent risk factors of unplanned readmission are shown in Table 4. After adjusting for other characteristics, independent predictors of readmission were emergency surgery $(p=0.016, \mathrm{OR}=2.73 ; 95 \%$ $\mathrm{CI}=1.35-6.19)$, major complications $(p=0.042$, OR $=$ 2.43; $95 \% \mathrm{CI}=1.12-4.71)$ and the initial length of hospital stay $(p=0.036, \mathrm{OR}=3.46 ; 95 \% \mathrm{CI}=1.67-7.53)$. The surgeon's skill level, which was related to the unplanned readmission in univariate comparison $(p=$ 0.048), was no longer significant association with the unplanned readmission in the multivariate analysis.

\section{Discussion}

With the increased attention placed upon readmission, it is essential to understand risk factors to deliver postoperative care for quality improvement, which has expanded to pediatric postoperative care [10-12]. The current study represents the first investigation to explore the contributing risk factors for unplanned readmission toward the development of strategies in pediatric patients who have undergone a variety of operations in a general surgical department. We demonstrated that the unplanned readmission were associated with more operative blood loss, faced a health emergency, or had more postoperative complications. Across pediatric surgical specialties, the common reasons for unplanned readmission were postoperative ileus and adhesion, postoperative biliary tract infection and wound problems.

Our overall readmission rate of $6.9 \%$ was consistent with the previously published readmission rate of $5.2 \%$ after general surgical procedures in pediatric population [13]. In the USA, for general pediatric surgery, the unplanned readmission rates are $4.4-6.5 \%[14,15]$. Differences in sample size and cases in the aforementioned studies compared with the current study may account 
Table 3 Univariate analysis of factors associated with unplanned readmission

\begin{tabular}{|c|c|c|c|}
\hline & \multicolumn{3}{|c|}{ Total population } \\
\hline & Control (338) & Unplanned readmission (176) & $p$ values \\
\hline Age (yrs) & $3.58 \pm 3.63$ & $3.56 \pm 3.73$ & 0.96 \\
\hline Male: female & 216:122 & 107:69 & 0.49 \\
\hline Operative time (mins) & $96.9 \pm 55.2$ & $105.5 \pm 58.6$ & 0.10 \\
\hline Operative blood loss (mL) & $9.3 \pm 5.1$ & $12.7 \pm 8.3$ & 0.039 \\
\hline Emergency surgery, n (\%) & $141(41.7)$ & $96(54.5)$ & 0.004 \\
\hline \multicolumn{4}{|l|}{ Initial surgery-related risk level, n (\%) } \\
\hline Low & $206(60.9)$ & $95(54.0)$ & \multirow[t]{3}{*}{0.18} \\
\hline Intermediate & $107(31.7)$ & $70(39.8)$ & \\
\hline high & $25(7.4)$ & $11(6.3)$ & \\
\hline \multicolumn{4}{|l|}{ ASA classification, n (\%) } \\
\hline ASA1 & $39(11.5)$ & $15(8.5)$ & \multirow[t]{4}{*}{0.35} \\
\hline ASA2 & $171(50.6)$ & $90(51.1)$ & \\
\hline ASA3 & $123(36.4)$ & $66(37.5)$ & \\
\hline ASA4 & $5(1.5)$ & $5(2.9)$ & \\
\hline \multicolumn{4}{|l|}{ Surgeons level, n (\%) } \\
\hline Resident & $85(25.1)$ & $47(26.7)$ & \multirow[t]{4}{*}{0.048} \\
\hline Senior Resident & $82(24.3)$ & $31(17.6)$ & \\
\hline Fellow & $125(37.0)$ & $83(47.2)$ & \\
\hline Attending & $46(13.6)$ & $15(8.5)$ & \\
\hline Operation on weekend, n (\%) & $53(15.7)$ & $30(17.0)$ & 0.69 \\
\hline Time of Case Start (6 pm-7 am), n (\%) & $124(36.7)$ & $57(32.4)$ & 0.33 \\
\hline Contaminated or dirty wound, $\mathrm{n}(\%)$ & $132(39.1)$ & $83(47.2)$ & 0.047 \\
\hline Major complications,n(\%) & $58(17.2)$ & $16(9.1)$ & 0.008 \\
\hline Infectious complications, n(\%) & $91(26.9)$ & $33(18.8)$ & 0.025 \\
\hline The initial hospital length of stay (days) & $10.2 \pm 5.7$ & $12.9 \pm 5.3$ & 0.011 \\
\hline
\end{tabular}

for some of the differences in the readmission rates. You know, in China, due to the economic backward and imperfect of health insurance, readmissions may be influenced because some of patients could not afford the medical expense and select discharge in advance. The self-discharged patients implied the managements were interrupted, which should be the risk for the unplanned readmission. The Pediatric National Surgical Quality

Table 4 Multivariable analyses of the factors with unplanned readmission

\begin{tabular}{llll}
\hline Scheduled & $p$ values & OR & $95 \% \mathrm{Cl}$ \\
\hline Emergency surgery & 0.016 & 2.73 & $1.35-6.19$ \\
Major complications & 0.042 & 2.43 & $1.12-4.71$ \\
The initial hospital length of stay & 0.036 & 3.46 & $1.67-7.53$ \\
\hline
\end{tabular}

The variables in the multivariable analyses included operative time, operative blood loss, emergency surgery, initial surgery-related risk level, surgeons level, contaminated or dirty wound, major complications, Infectious complications, the initial hospital length of stay. Only significant risk factors for related or unrelated readmissions are shown $(P<.005)$
Improvement Program (NSQIP-P) includes major procedures that might bias toward higher reports of readmission for increased frequency of the occurrences of postoperative complications. In the current data, the appendectomies and laparotomy operations were the most common surgeries, which were related to unplanned readmission. A similar distribution of procedures, involved in unplanned readmission was present in a number of other studies [16, 17]. Reducing readmission rates and designing interventions would be important for pediatric surgical patients. The current $1.5 \%$ of planned readmission was consistent with that reported by others [18].

For quality improvement, identification the greater risks carried by which postoperative complications would be beneficial to prevent readmissions. Our research provided a retrospective unplanned readmission review and determined the reasons for readmission. While the reasons for unplanned readmission varied by different specialty, the current research supported the conclusion that postoperative ileus and adhesion were 
the most common reasons for readmission within general pediatric surgery, which was similar to the reported reasons of others [13, 14]. Gastrointestinal-related causes were the most common reasons for readmission, accounting for one-third of readmissions. Consequently, the most frequently performed procedure during readmissions was enterolysis. This finding contrasts with the findings for adults, for whom surgical site infections represented the leading cause of readmission among general surgery procedures [19]. In our institute, the adhesion events were treated with cautions. Some mild obstructive symptoms were readmitted for fluid resuscitation, which might account for the current high rate of postoperative intestinal adhesions. The indication for postoperative intestinal adhesions involved fluid resuscitation as well as attitudes toward readmission warrant further investigation and present opportunities for quality improvement. After postoperative intestinal adhesions, postoperative surgical site infection (SSI) was the next most frequent cause related to readmission. Recently, it was reported that over $50 \%$ of the patients following general surgical procedure readmitted due to a SSI [20]. Additionally, an operative time greater than $4 \mathrm{~h}$ conferred increased risk for SSI [20]. Operative approach and the transfusion of blood products depend on clinical manifestation and surgical judgment and technique. To decrease the readmissions, multidisciplinary efforts by operative surgeon, physicians and nurses should be focused on these modifiable risk factors perioperatively.

Our study provides further evidence that operative blood loss, emergency surgery and complications are the most predictive for hospital readmissions [2, 21]. Most risk factors, such as severe condition and massive surgery, were either nonmodifiable comorbidities or markers for severe underlying illness, which is not surprising. For instance, emergency surgery was a risk factor in our study [1]. However, in this research, less intuitive factors were also associated with substantial risk, such as longer length of stay and different surgeon skill levels. We found that readmission was two times when the procedure was performed with higher level surgeons. Although some authors have not found this association, which should be a potentially causative modifiable risk factor, this finding implied that strict quality control should be undertaken in our institute. After general surgery procedures, it was identified that shorter length of stay was predisposed toward readmission in some research [22]. In fact, the current data suggested that multiple complications was associated with longer length of stay and more readmission, which was also present following bariatric surgery and colorectal surgery [23, 24]. The patient's comorbidities should drive the longer length of stay, which might also account for the readmission increase. Implications the current finding is that many of readmissions may be avoidable in a certain part of patients, which presents an opportunity to improve quality and the delivery of outpatient care or improved educational processes in our institute. The insight obtained from readmission can help support or refute the efficacy of a protocol applied across the initial operations and develop new surgical methods in the context of regular complication control. In addition, the lessons learned can be of great value in teaching young clinicians [25].

There are limitations in certain aspects of our study. First, our study has a limitation inherent to retrospective nature wherein selection bias could be confounding, which might restrict the generalizability of the current conclusions. The current data were gathered from our single general surgical department, reflecting the experience only from our institution. Although most of patients are back to our institution for further care, some of readmittion might get into local hospitals. Thus, the current real readmission may be higher than the estimated one. Finally, the lack of readmission information for specific operation is another weakness of the current research, which might help to identify high risk of operation for readmission.

\section{Conclusion}

We uncovered the common reasons for unplanned readmissions at our institution, namely, infection and hemorrhage. We also identified the risk factors for unplanned readmissions following general surgery in a pediatric patient population. A standardized, well-defined registry of all unplanned readmissions classified by type of index operation is important for the care quality improvement across a large population of infants and children.

\section{Abbreviations}

Cl: Confidence interval; GI: Gastrointestinal; OR: Odds ratio; SSI: Surgical site infection

\section{Acknowledgements}

We thank Prof. Xianqing Jin for providing insightful discussions about the manuscript. We thank Dr. Xiaoyong Zhang (the Wistar Institute, USA) for his linguistic revision of the manuscript.

\section{Authors' contributions}

$\mathrm{CZ}, \mathrm{LQ}$ and $\mathrm{HZ}$ designed the study and analyzed the data. BC and $\mathrm{HZ}$ evaluated the manuscript. CG and $\mathrm{HZ}$ performed the statistical measurement and analyzed the data. CG analyzed the data and wrote the paper. All authors have read and approved the final manuscript as submitted and agree to be accountable for all aspects of the work.

\section{Funding}

This study was supported by the grants from the National Natural Science Foundation of China (No: 30973440, 30770950) in the design of the study, the Key Project of the Chongqing Natural Science Foundation (CSTC, 2008BA0021, cstc2012jjA0155) for collection, analysis, and interpretation of data and Chongqing Health Planning Commission of Research Fund (No: 2016MSXM044) in writing the manuscript.

Availability of data and materials

The datasets during and/or analyzed during the current study are available from the corresponding author on reasonable request. 


\section{Ethics approval and consent to participate}

This study was exempted from review by the institutional review board at the Chongqing Medical University, and the requirement for informed consent was waived given the retrospective design of the study.

\section{Consent for publication}

Not applicable.

\section{Competing interests}

The authors declare that they have no competing interests.

\section{Author details}

'Department of Pediatric General Surgery, Children's Hospital, Chongqing Medical University, Chongqing, People's Republic of China. ${ }^{2}$ Ministry of Education Key Laboratory of Child Development and Disorders, Children's Hospital, Chongqing Medical University, 136, 2nd Rd. Chongqing, Zhongshan 400014, People's Republic of China.

Received: 25 November 2018 Accepted: 15 August 2019

Published online: 26 September 2019

\section{References}

1. Berry JG, Toomey SL, Zaslavsky AM, Jha AK, Nakamura MM, Klein DJ, Feng JY, Shulman S, Chiang WW, Kaplan W, Hall M, Schuster MA. Pediatric readmission prevalence and variability across hospitals. JAMA. 2013;309:372-80.

2. Kassin MT, Owen RM, Perez SD, Leeds I, Cox JC, Schnier K, Sadiraj V, Sweeney JF. Risk factors for 30-day hospital readmission among general surgery patients. J Am Coll Surg. 2012;215(3):322-30.

3. Sinha CK, Decker E, Rex D, Mukhtar Z, Murphy F, Nicholls E, Okoye B, Giuliani S. Thirty-days readmissions in pediatric surgery: the first U.K. experience. J Pediatr Surg. 2016;51(11):1877-80.

4. Adeyemo D, Radley S. Unplanned general surgical re-admissions - how many, which patients and why? Ann R Coll Surg Engl. 2007:89:363-7.

5. Friedman B, Basu J. The rate and cost of hospital readmissions for preventable conditions. Med Care Res Rev. 2004;61:225-40.

6. Jencks SF, Williams MV, Coleman EA. Rehospitalizations among patients in the Medicare fee-for-service program. N Engl J Med. 2009:360(14):1418-28

7. Hendren S, Morris AM, Zhang W, Dimick J. Early discharge and hospital readmission after colectomy for cancer. Dis Colon Rectum. 2011;54:1362-7.

8. Schilling PL, Dimick JB, Birkmeyer JD. Prioritizing quality improvement in general surgery. J Am Coll Surg. 2008;207:698-704.

9. Havens JM, Olufajo OA, Cooper ZR, Haider AH, Shah AA, Salim A. Defining rates and risk factors for readmissions following emergency general surgery. JAMA Surg. 2016;151(4):330-6.

10. Sills MR, Hall M, Colvin JD, Macy ML, Cutler GJ, Bettenhausen JL, Morse RB, Auger KA, Raphael JL, Gottlieb LM, Fieldston ES, Shah SS. Association of social determinants with children's hospitals' preventable readmissions performance. JAMA Pediatr. 2016;170:350-8.

11. Han S, Smith TS, Gunnar W. Descriptive analysis of 30-day readmission after inpatient surgery discharge in the veterans health administration. JAMA Surg. 2014;149(11):1162-8.

12. Bardach NS, Vittinghoff E, Asteria-Peñaloza R, Edwards JD, Yazdany J, Lee HC, Boscardin WJ, Cabana MD, Dudley RA. Measuring hospital quality using pediatric readmission and revisit rates. Pediatrics. 2013;132:429-36.

13. Kulaylat AN, Rocourt DV, Tsai AY, Martin KL, Engbrecht BW, Santos MC, Cilley RE, Hollenbeak CS, Dillon PW. Understanding readmissions in children undergoing surgery: a pediatric NSQIP analysis. J Pediatr Surg. 2018;53(7): $1280-7$

14. Brown EG, Anderson JE, Burgess D, Bold RJ, Farmer DL. Pediatric surgical readmissions: are they truly preventable? J Pediatr Surg. 2017;52:161-5.

15. Burjonrappa S, Theodorus A, Shah A, Cohen IT. Pediatric surgery readmissions: a root cause analysis. Pediatr Surg Int. 2015;31:551-5.

16. Gay JC, Agrawal R, Auger KA, Del Beccaro MA, Eghtesady P, Fieldston ES, Golias J, Hain PD, McClead R, Morse RB, Neuman MI, Simon HK, TejedorSojo J, Teufel RJ 2nd, Harris JM 2nd, Shah SS. Rates and impact of potentially preventable readmissions at children's hospitals. J Pediatr. 2015; 166(3):613-9 e5.

17. Rice-Townsend S, Hall M, Barnes JN, Baxter JK, Rangel SJ. Hospital readmission after management of appendicitis at freestanding children's hospitals: contemporary trends and financial implications. J Pediatr Surg. 2012:47:1170-6.
18. Zhang JQ, Curran T, MCCallum JC, Wang L, Wyers MC, Hamdan AD, Guzman $\mathrm{RJ}$, Schermerhorn ML, et al. Risk factors for readmission after lower extremity bypass in the American College of Surgeons National Surgery Quality Improvement Program. J Vasc Surg. 2014;59:1331-9.

19. Merkow RP, Ju MH, Chung JW, Hall BL, Cohen ME, Williams MV, Tsai TC, Ko $\mathrm{CY}$, Bilimoria KY. Underlying reasons associated with hospital readmission following surgery in the United States. JAMA. 2015;313:483-95.

20. Gibson A, Tevis S, Kennedy G. Readmission after delayed diagnosis of surgical site infection: a focus on prevention using the American College of Surgeons National Surgical Quality Improvement Program. Am J Surg. 2014; 207(6):832-9.

21. Tevis SE, Kohlnhofer BM, Weber SM, Kennedy GD. Postdischarge complications are an important predictor of postoperative readmissions. Am J Surg. 2014;208(4):505-10.

22. Kohlnhofer BM, Tevis SE, Weber SM, Kennedy GD. Multiple complications and short length of stay are associated with postoperative readmissions. Am J Surg. 2014;207(4):449-56.

23. Wick EC, Shore AD, Hirose K, Ibrahim AM, Gearhart SL, Efron J, Weiner JP, Makary MA. Readmission rates and cost following colorectal surgery. Dis Colon Rectum. 2011;54:1475-9.

24. Dorman RB, Miller CJ, Leslie DB, Serrot FJ, Slusarek B, Buchwald H, Connett $J E$, Ikramuddin S. Risk for hospital readmission following bariatric surgery. PLoS One. 2012;7(3):e32506.

25. Osborne NH, Nicholas LH, Ryan AM, Thumma JR, Dimick JB. Association of hospital participation in a quality reporting program with surgical outcomes and expenditures for Medicare beneficiaries. JAMA. 2015;313(5):496-504

\section{Publisher's Note}

Springer Nature remains neutral with regard to jurisdictional claims in published maps and institutional affiliations.

Ready to submit your research? Choose BMC and benefit from:

- fast, convenient online submission

- thorough peer review by experienced researchers in your field

- rapid publication on acceptance

- support for research data, including large and complex data types

- gold Open Access which fosters wider collaboration and increased citations

- maximum visibility for your research: over $100 \mathrm{M}$ website views per year

At BMC, research is always in progress.

Learn more biomedcentral.com/submissions 